\title{
Laser-induced incandescence (LII)
}

\author{
K. Thomson
}

Published online: 16 July 2009

(C) Springer-Verlag 2009

Laser-induced incandescence (LII) has proven to be a powerful tool for particle concentration and particle size measurements in combustion, particle synthesis, as well as in environmental applications. However, different experimental approaches and data evaluation techniques exist which, while demonstrating the complexity of the physical processes involved in LII and the need for further research, have also somewhat inhibited the acceptance by industry of LII as a measurement standard. In order to strengthen the community and to explore the development of a series of best practices for LII modelling, experiments, and data interpretation, a series of workshops was initiated. The initial workshop, in September 2005 in Duisburg, Germany, was a successful meeting of many of the significant international contributors to LII research. A selection of peer reviewed papers from the meeting were included in a special edition of Applied Physics B, volume 83, number 3. The second workshop was held in August 2006 in Bad Herrenalb, Germany. This meeting demonstrated reductions in the differences in the models relative to the first workshop, and some best practices in experimental methods.
Nanoparticle measurement as related to health, the environment, and engineered particle synthesis remains a current and pressing concern and the Third International Workshop on Laser-Induced Incandescence: Quantitative Interpretation, Modeling, Application was held in 2008 in Ottawa, Canada, to further the advancement of the fundamental understanding of LII.

This feature issue in Applied Physics B is a review of the current status of LII as discussed during the third LII workshop and includes 11 selected peer-reviewed papers that were presented at the conference. These papers cover the themes of the influences of various experimental parameters on the accuracy of LII measurements, signal interpretation, LII applied to non-soot nanoparticles, and the combination of LII with elastic light scatter.

We are grateful to Editor-in-Chief Frank Träger and Jutta Kaisig of the University of Kassel for their advice and support in producing this special issue.

K. Thomson ( $\varangle$ )

ICPET, National Research Council Canada, Ottawa, ON,

K1A 0R6, Canada

e-mail: kevin.thomson@nrc-cnrc.gc.ca

Fax: +1-613-9577869 